\title{
UN PACTO CON LA FELICIDAD: RESISTENCIAS ÍNTIMAS EN LA ÚLTIMA POESÍA DE ELOY SÁNCHEZ ROSILLO ${ }^{1}$
}

\author{
A PACT WITH HAPPINESS: INTIMATE RESISTANCES \\ IN ELOY SÁNCHEZ ROSILLO'S LAST POETRY
}

Borja CANO VIDAL ${ }^{2}$

Universidad de Salamanca

borjacano@usal.es

Resumen: La voz poética de Eloy Sánchez Rosillo (Murcia, 1948) es considerada una de las más singulares y destacadas del panorama de la lírica española contemporánea. A partir de la publicación de La certeza (2005), su estética, hasta entonces ligada a un tono elegíaco y melancólico, experimentó un giro en el que lo celebratorio, el carácter hímnico y el canto a la plenitud del instante y del presente se han convertido en sus características más señaladas. El presente artículo ahonda, en relación con esta peculiaridad, en la composición y expresión de una poética de la felicidad y en los principales ejes que la edifican. Así, el recuerdo de los veranos de su infancia y los diferentes pájaros que a ellos le recuerdan, junto al elemento de la cotidianidad, forman los principales actos de resistencia íntima en los que el poeta encuentra su principal asidero para vivir en el instante inmenso que para él constituye el presente.

Palabras clave: Eloy Sánchez Rosillo; poesía española contemporánea; felicidad; intimidad; cotianidad.

Abstract: The poetical voice of Eloy Sánchez Rosillo (Murcia, 1948) is considered to be one of the most singular and emphasized from the panorama of the Spanish contemporary poetry. From the publication of La certeza (2015), his aesthetics, till then tied to an elegiac and melancholy tone, experienced a draft in which the celebratory, the hymnic character and the singing to the fullness of

\footnotetext{
${ }^{1}$ Este trabajo se inserta dentro del marco del proyecto de investigación «Felicidad y literatura: eficacia social del discurso literario» (Programa IB, Universidad de Salamanca, 2016/2017), en cofinanciación con la Conserjería de Educación de la Junta de Castilla y León.

${ }^{2}$ Este trabajo ha sido realizado gracias a la obtención de un contrato predoctoral mediante la convocatoria de «Ayudas para financiar la contratación predoctoral de personal investigador» (2017) de la Junta de Castilla y León a través de la Consejería de Educación, en cofinanciación con el Fondo Social Europeo (Programa Operativo de Castilla y León).
} 
the instant and of the present have turned into his more notable characteristics. This papers goes deeply, in relation whit this peculiarity, into the composition and expression of a poetics of happiness and in the principal axes that build it. This way, the summer recollection of his infancy and the different birds that them they him resemble, close to the element of the commonness, form the principal acts of intimate resistance in which the poet finds his principal handle to live in the immense instant that for him constitutes the present.

Keywords: Eloy Sánchez Rosillo; spanish contemporary poetry; happiness; intimacy; commonness. 
porque hasta el tiempo, ese pariente pobre que conoció mejores días, parece hoy partidario de la felicidad

Jaime Gil de Biedma

\section{I} ntroducción

En su ensayo L'intuition de l'instant (1979), Gaston Bachelard reivindicaba la supremacía del instante frente a la duración, en una esfera temporal discontinua en la que la realidad se asienta en la inmovilidad y despreocupada experiencia que contiene el instante. Décadas más tarde, y en un contexto diferente, el poeta murciano Eloy Sánchez Rosillo (1948) afirma: «El tiempo es ahora tiempo entero, un instante inmenso e indivisible en el que todo se nos da simultáneamente y en el que latimos al unísono con las cosas del mundo. La vida no transcurre; la vida es» (Mora Fandos, 2017). Esta veneración del momento presente, junto a la aceptación serena de su realidad, «no se trata de un cántico jubiloso y estridente, sino más bien una afirmación, una sosegada alegría de estar vivo» (Lanseros Sánchez, 2017), cuya concepción del tiempo ha experimentado un importante giro que ha reverberado también en su producción poética ${ }^{3}$.

Tal pensamiento, sin embargo, no constituye una constante en toda la obra de Sánchez Rosillo, sino que se corresponde con su última etapa, tanto poética como personal, pues en el caso de Rosillo ambos caminos deben entenderse casi de manera conjunta. Él mismo ha insistido en esta cuestión en diversas entrevistas (Mora Fandos, 2017):

Yo tenía de joven una concepción lineal del tiempo: presente fugacísimo, pasado en el que las cosas que una vez fueron nuestras se desdibujan y terminan por desaparecer, futuro inconsistente e incierto que no es más que humo. Y todo transcurriendo a una velocidad increíble, como la corriente imparable de un río vertiginoso.

Desde esta consideración, cabe resaltar que tras recibir el Premio Adonáis de Poesía en 1977 con su primer libro Maneras de estar solo (1978), Sánchez Rosillo fue rápidamente catalogado dentro de aquellos poetas que, cercanos a las relecturas de la tradición clásica, experimentaban en sus obras un claro discurso elegíaco (Bagué Quílez, 2003). Por este motivo, no sorprende que de forma unánime la crítica haya mostrado un creciente interés por el giro que en su poesía puede percibirse tras la publicación de La certeza (2005) tras casi una década de silencio. El propio Sánchez Rosillo, consciente de ello, ha hablado en más de una ocasión sobre este asunto, si bien él mismo rechaza la idea de que tal hecho haya supuesto una escisión en su obra, al menos no radical: «En mi evolución no ha habido volteretas ni cabriolas efectistas. Hay que crecer como los árboles, a los que de un día para otro no se les ve crecer» (Fontana, 2013). De esta forma, no podemos entender este cambio de

\footnotetext{
${ }^{3}$ Para un estudio más exhaustivo de su concepción del tiempo y cómo esta se ha desarrollado a lo largo de toda su poesía, resulta de interés resaltar el trabajo de Lanseros Sánchez (2017), donde examina los motivos estéticos e incluso personales de tal progreso.
} 
discurrir estético en claves de transgresión o transformación radical, sino como él mismo lo considera: un proceso lento, análogo a su madurez tanto personal como poética.

Así pues, y aunque la poesía de Eloy Sánchez Rosillo nunca ha terminado de identificarse con las tendencias estéticas imperantes de cada momento, es cierto que el giro que ha experimentado su producción y sentir poéticos camina en una línea pareja a la de otros autores que, procedentes de diversas corrientes, han convergido en el siglo XXI en una vertiente vital en la que la celebración de la existencia, la intimidad o una melancolía sorprendentemente feliz perviven en una poética que lo sitúa entre uno de los autores más singulares del panorama lírico hispánico actual. Desde este planteamiento, el presente trabajo se propone como objetivo ahondar en la caracterización estética que en los últimos libros de Eloy Sánchez Rosillo contiene este pacto con la felicidad que ya, de forma decisiva, encierra su poesía.

Si bien ha sido de sobra señalado este giro, resulta necesario trazar una tentativa de análisis de cómo esta poética se construye en su obra, así como ponerla en relación con aquellas que en los últimos años parecen discurrir por sendas similares y, por tanto, preguntarse por sus significantes y significados. Para ello, tras la pertinente contextualización y puesta en clave con su contexto, serán dos los aspectos más representativos a tratar: por un lado, la extraña, pero efectiva combinación del discurso melancólico e hímnico y, por otro, la presencia del elemento cotidiano - especialmente visible en la aparición de diferentes pájaros que remiten a la infancia del poeta-, y alguno de sus enclaves más señalados. Por último, cabe resaltar que serán objeto de estudio en este artículo tan solo sus últimos poemarios publicados, partiendo de la consideración de que constituyen el mayor y más fiel reflejo de la poética de la felicidad que será expuesta a lo largo de las próximas páginas ${ }^{4}$.

\section{Poéticas contra la intemperie: felicidad e incertidumbre en la poesía española contemporánea}

Las propuestas que plantean la poesía como salvaguarda de un horizonte borroso son cada vez más frecuentes en el panorama español actual, donde destaca una cierta confrontación a la intemperie del mundo contemporáneo como una de sus características preponderantes. Se trata, a fin de cuentas, de un derrumbe de los esquemas éticos, que Jacobo Muñoz ha denominado como el «desasosiego moderno» y que vendría a suponer «el fin de todo proyecto y normativa histórica totalizante» (2004: 299). Ante esta situación de incertidumbre, la poesía española presenta, en los últimos años, un auge cada vez mayor de ciertas propuestas que encuentran en el presente y el goce del instante el asidero necesario ante un mundo que se muestra incierto. Es el caso, por ejemplo, de la obra de José Luis Puerto, quien desde el beatus ille que le proporciona el municipio salmantino de La Alberca ha sustituido en sus últimos poemarios el recuerdo de lo perdido por un canto al instante y ha instituido

\footnotetext{
${ }^{4}$ En concreto, se trata de La certeza (2005), Oír la luz (2008), Sueño del origen (2011), Antes del nombre (2013) y Quién lo diría (2015). No forman parte del corpus principal, por tanto, sus anteriores obras, si bien todas ellas fundamentan de manera decisiva tanto el recorrido poético como vital de Sánchez Rosillo y, por tanto, no deben dejarse de lado. Son: Maneras de estar solo (1978), Páginas de un diario (1981), Elegías (1984), Autorretratos (1989), La vida (1996), La certeza (2005) y Oír la luz (2008). Recuérdese, igualmente, la publicación de su antología Las cosas como fueron (2004), que recogió su trayectoria desde 1974 hasta el año 2003.
} 
una firme creencia en que la poesía puede salvarnos de esta intemperie que impone la crudeza del

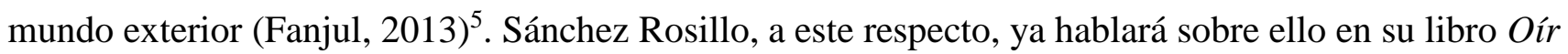
la luz (2008: 115-116):

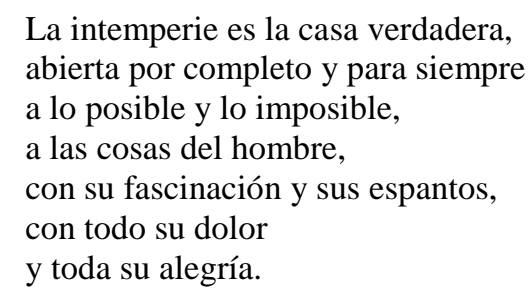

En su último poemario publicado, Quién lo diría, remite de nuevo a esta intemperie del mundo que le rodea y de la que el poeta es plenamente consciente, aunque en esta ocasión asume la posibilidad de salvación mediante la serena celebración del vivir: «[...] no hay intemperie/ cuando con firme pie/ y afanosa retina/ nos adentramos en los incontables/ e ingentes aposentos del asombro» (Sánchez Rosillo, 2015: 17). Desde este planteamiento, el alejamiento de ciertas tendencias estéticas más cercanas al culturalismo declina en favor de una poesía que cada vez se muestra más cercana a su mundo (García Montero, 1996: 70) y que, además, se ofrece como clave no solo de reflexión, sino también de bálsamo ante la realidad ya mencionada. Esta crisis del malestar, junto a la sensación de apatía que han caracterizado los últimos años al individuo occidental, muestran la necesidad de repensar conceptos e ideas como la felicidad, la serenidad, la alegría o la celebración, en un proceso que, si bien no proporcionará mayor seguridad, sí dará esperanza (García-Baró, 2012) ${ }^{6}$; ahí es, entonces, donde aparece la poesía.

Esta nueva forma de estar en el mundo presenta en la actualidad, entonces, un gran rendimiento. Buen ejemplo de ello es la cada vez más prolífica producción poética en torno a estas cuestiones, con nombres como los del salmantino Juan Antonio González Iglesias, quien integra la exaltación amorosa o el goce corporal en busca de una felicidad serena, o la poesía de Aurora Luque, cuya propuesta de un carpe noctem y carpe amorem «permite actualizar la lección hedonista de los clásicos en las actividades prosaicas de la vida cotidiana» (Bagué Quílez, 2008: 55). Junto a ellos, cabe llamar la atención sobre otros muchos - Francisco Ruiz Noguera, Andrés Neuman, Amalia Bautista o Leopoldo Sánchez Torre - así como Eloy Sánchez Rosillo, quien ocupa estas líneas y se incluye en una lista que reúne cada vez un número más elevado de autores. Se trata, pues, de «considerar el hedonismo uno de los factores esenciales de la vida social que está (re)naciendo en las sociedades

\footnotetext{
${ }^{5}$ De hecho, el título de sus últimos poemarios ya da buena cuenta de este hecho: De la intemperie (2004), Proteger las moradas (2004) y Trazar la salvaguarda (2012).

${ }^{6}$ Este filósofo español acude al ideal del «bien perfecto» de la filosofía clásica para desarrollar sus ensayos en torno a este tipo de nociones. Además de él, son varios los pensadores del panorama español actual que han reflexionado acerca de la felicidad o asuntos parejos a ella, como Fernando Savater, Adela Cortina o Esperanza Guisán. Cada uno diferente del otro, y algunos disidentes entre sí, la conclusión a la que cabe llegar es que nos encontramos ante una nueva generación que, si bien no ha sufrido en primera persona una guerra entendida en su sentido más estricto, se siente inundada por el horror y la crueldad.
} 


\section{Tropelías. Revista de Teoría de la Literatura y Literatura Comparada, 30 (2018) \\ Un pacto con la felicidad: resistencias íntimas en la última poesía de Eloy Sánchez Rosillo}

contemporáneas» (Maffesoli, 1996: 7), precisamente gracias el individuo actual puede encontrar su pequeño intersticio de felicidad.

De igual forma, el refugio íntimo se considera el espacio por excelencia del que asirse, en el que existe la posibilidad de crear una «yo-topía» (Fajardo, 2007); es decir, aquellas utopías contemporáneas que buscan el lugar del bien en su espacio individual, algo que a su vez conecta con las «microutopies interstitielles» que propone el sociólogo francés Michel Maffesoli ${ }^{7}$ (1993), ante la gran crisis de valores existente. Ante la creación de este propio espacio en el seno de la vida cotidiana, resta preguntarse el por qué la poesía parece ser el lenguaje adoptado con mayor frecuencia en la elaboración y plasmación de estos nuevos discursos. Al respecto, resulta de interés aludir al siguiente fragmento de Jorge Riechmann (2013: 32):

¿Qué nos recuerda la poesía? Que lo esencial de la vida, lo que realmente importa, es algo que está más allá de la estadística y la máquina, de la prisa y las ocupaciones, del ruido y el progreso: algo que tiene que ver con la respiración, el vínculo y el silencio. Y que ese algo difícil de cerner está siempre ahí.

Desde este planteamiento, la pertinencia por parte de la poesía para expresar estas nuevas relaciones simbólicas conecta, a su vez, con la fecunda producción de tales cuestiones. En este sentido, destaca la publicación, por parte de la editorial Visor en 2011, de la antología Poesía ante la incertidumbre, donde se presentan una serie de nuevas voces en el panorama lírico español que reivindican una defensa de la utilidad de la poesía para ofrecer un panorama más humano ante la situación de desasosiego actual que gobierna en todos los ámbitos. A continuación, ofrezco un extracto que, aunque algo extenso, resulta tremendamente certero en lo anteriormente expuesto (2011: 7):

El momento de la Historia que nos ha tocado vivir está marcado por la incertidumbre en todos los sentidos. Cuando pensábamos que el siglo XX agonizaba y con él los grandes temores y catástrofes capaces de minar la fe en la humanidad, no han surgido los puentes que destruyan nuestros precipicios. Al contrario, resulta más difícil intuirlos, imaginarlos. La incertidumbre parece abarcarlo todo: la política, la moral, la economía, las nuevas formas de comunicación que paradójicamente han provocado una mayor incomunicación... También las viejas utopías que parecieron realizables y llenaron de ilusión a millones de ciudadanos se han desmoronado mostrando sus miserias cuando han sido suplantadas por los hombres, añadiendo aún más incertidumbre a todo lo que nos rodea.

Nuestra generación está marcada por esta incertidumbre y creemos que es necesario hacer un alto en el camino, reflexionar, mirarnos a los ojos, establecer una cercanía menos artificial, más humana. La poesía puede arrojar algo de luz para alcanzar algunas certidumbres necesarias.

Esta incertidumbre, por tanto, no es más que un sinónimo de lo que otros autores han denominado intemperie, signando ambas una misma realidad de la que los textos contemporáneos se muestran plenamente conscientes. Se trata, entonces, de autores que se declaran partidarios de la felicidad, como ya reivindicara Jaime Gil de Biedma en los versos que encabezan este trabajo, y que con la lucidez de aquel que conoce con seguridad su tiempo, rechazan la expresión de tales condicionantes a través de

\footnotetext{
${ }^{7}$ El sociólogo francés, director del Centre de Recherche sur l'Actuel et le Quotidien, ha centrado sus esfuerzos en desarrollar una teoría que defiende la preponderancia de la razón sensible por encima de la lógica en nuestro mundo contemporáneo, y en la que aclama la emergencia de «microutopies interstitielles» que permiten al individuo el resquicio humano y emocional que el fin de todos los paradigmas y posibilidades utópicas borró (Maffesoli, 1993: 140-141).
} 
sus obras y deciden ofrecer un alto en el camino que invite a la reflexión y a la mera celebración de lo cotidiano como salvoconducto ante una crisis que rige todos los niveles posibles.

\section{Un pacto con la vida: el carácter hímnico de la última poesía de Eloy Sánchez Rosillo}

Ya se ha apuntado de forma breve con anterioridad el giro que experimentó la poesía del escritor murciano a partir de la publicación de La certeza (2005) y que se expandirá a sus obras posteriores de forma mucho más nítida. Aunque es cierto que en numerosas entrevistas y publicaciones acerca de este hecho se ha insistido en la idea de evolución o transgresión por parte de Sánchez Rosillo, considero que no se trata de un quiebre absoluto, sino más bien, en palabras de Pozuelo Yvancos, «modificaciones tonales» (2007: 29); no obstante, existe una serie de símbolos o claves estéticas que no han dejado nunca de aparecer entre sus versos. De igual forma, Prieto de Paula retoma esta idea y justifica el cambio de registro poético aludiendo al carácter constantemente biográfico y dependiente de sus propios asuntos que tiene Eloy Sánchez Rosillo (2007: 101), lo que, evidentemente, implica un cambio notorio al mismo ritmo que el decurso vivencial. Se trata, pues, de contemplar la obra del autor murciano como una constante evolución en la que la elegía nunca ha llegado a desaparecer, sino que ha declinado en favor de un carácter hímnico que, a su vez, no olvida ni deja de mencionar el pasado y el recuerdo de lo perdido8. A este respecto, las propias palabras de Sánchez Rosillo en una tentativa de poética resultan esclarecedoras (2005: 32-33):

Pero en el fondo las diferencias entre poesía elegíaca y la poesía hímnica o celebrativa no son tan sustanciales como parece, y a menudo ambas modalidades poéticas pueden darse de manera entremezclada en un mismo poema. En realidad, el poeta auténtico siempre celebra, porque es un enamorado de la vida. No hay más que una poesía verdadera, aunque existan, eso sí, temperamentos poéticos diversos. Elegía y celebración vienen a fin de cuentas a ser la misma cosa, aunque en una y otra la realidad sea enfocada desde ángulos distintos, o más bien desde tiempos diferentes. La poesía hímnica celebra la alegría de vivir y la hermosura del mundo en presente, mientras que la elegíaca efectúa similar celebración retardadamente, es decir, cuando lo que se pretende celebrar se encuentra ya concluido y en el pasado, en un más o menos remoto pretérito, de ahí se deriva por cierto su lamento y su tono melancólico.

Eloy Sánchez Rosillo, pues, aúna lamento y celebración mediante un estilo propio y singular en el que el discurrir lírico de carácter eminentemente autobiográfico le ha situado, con el paso de los años, en un estadio excepcional en el que el poeta se erige como una de las voces más destacadas de nuestro panorama peninsular9. Aquel sueño elegíaco en el que se mostraba inmerso en sus primeros libros, es ahora concreto y posee identidad, y no es sino la realidad que ante él se presenta y lo cotidiano de su acontecer. A este respecto destaca la apertura de Antes del nombre, que constituye toda una declaración de intenciones (Sánchez Rosillo, 2014):

\footnotetext{
${ }^{8}$ De este hecho da cuenta el poeta también en sus propios versos, quien afirma en Sueño del origen: «Supe de la añoranza y el lamento./ Ahora celebro y canto» (2011: 55).

${ }^{9}$ En este sentido, resulta de interés recordar el pensamiento de Claudio Magris, quien desarrolló la concepción de la historia literaria occidental de los últimos dos siglos en relación a dos términos: utopía y desencanto, que «antes que contraponerse, tienen que sostenerse y corregirse recíprocamente» (2001: 13). Se observa de nuevo, entonces, la discurrida dialéctica entre términos que antagónicamente se han opuesto, y que en el caso de Sánchez Rosillo nos remite a la elegía y a lo hímnico, a la tristeza y la alegría, la melancolía y la felicidad, prueba todo ello de la condición contemporánea del individuo.
} 


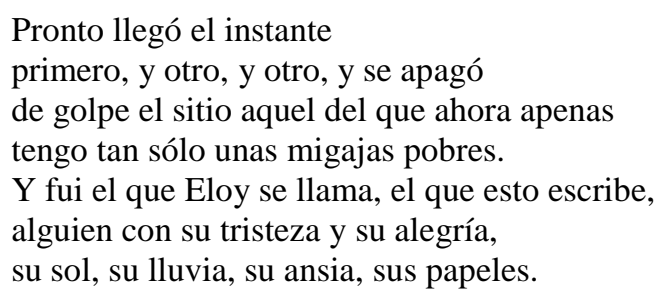

Este proceso, según el cual el sujeto asume su condición inestable de forma serena, responde a lo que Josep Maria Esquirol ha definido, en relación con el mundo contemporáneo, la «resistencia íntima», que no corresponde con la concepción del resistente que vincula al sujeto con la protesta, sino con una manera de ser esencialmente humana concerniente a la «fortaleza que podemos tener y levantar ante los procesos de desintegración y de corrosión que provienen del entorno e incluso de nosotros mismos» (2015: 10). Así pues, desde la calma que le concede saberse de vuelta del viaje del dolor y la melancolía, Sánchez Rosillo acepta impúdico su quietud, que no es otra cosa que una alternativa, una resistencia íntima que resulta ser el asidero, como él mismo indica, «En la profunda calma»: «Todo es presente vivo y palpitante/ que quisiera ser dicho./ Y yo no quiero sino pronunciarlo» (2011: 17). Sánchez Rosillo, por tanto, adquiere desde su privilegiada condición de poeta una posición de sujeto himnario, desde la cual esa «filosofía de la proximidad» a la que alude el filósofo Esquirol le concede la palabra y su poder resistente de esta ante el desasosiego contemporáneo.

Así, la literatura, y en este caso concreto la poesía, se erigen como el discurso más eficaz para desarrollar esta poética del bien en la que resulta necesario enmarcar la figura de Eloy Sánchez Rosillo, quien de forma sobresaliente y singular ha desarrollado un proceso por el que melancolía y felicidad se dan de la mano y conviven armoniosamente, tal y como también ha advertido Cambronero Armero (2012). El poeta, pues, se considera un hombre «sin edad», en el que habitan la dicha y la melancolía y, por ello, concluye: «[...] ninguna acaso/ quiere imponerse: se entrelazan ambas/ en un sentir más hondo y sin origen» (2015: 101). Esta poética alegre y serena, en el caso de Sánchez Rosillo, se configura a partir de una serie de motivos centrales que constituyen una constante en su obra, y entre los que destacan principalmente tres: la luz, el recuerdo de la infancia y los pájaros, todos ellos elementos que se abordan desde un mismo núcleo: la fuerza de lo cotidiano ${ }^{10}$.

Esta estética del bien se encuentra, para Rosillo, al alcance de todos y en la cotidianidad de la vida, a la que se accede tan solo con la mera observación del mundo que nos rodea. Así lo expone en uno de sus textos más clarificadores al respecto, que supone toda una invitación al «pacto luminoso de la vida» y que tan solo necesita «que haya en el corazón consentimiento/ para llegar hasta la luz del día». Este «Pacto con la vida» (2015: 93-94), por tanto, es también un acuerdo con la felicidad, y que

\footnotetext{
${ }^{10}$ Este último elemento comenzó a cobrar mayor protagonismo en todos los planos estéticos a lo largo del siglo XX, dando lugar a lo que se conoce como «estética cotidiana» (Pérez-Henao, 2014) y cuyas primeras discusiones se remontan a destacados pensadores en tal ámbito como Kupfer (1983) o Featherstone (1991), si bien ha sido quien ha señalado la cuestión de mayor importancia en lo que aquí respecta: la omnipresencia de imágenes en el mundo contemporáneo, lo que sin duda entronca con la poesía de Sánchez Rosillo. El poeta murciano, entonces, observa su mundo desde el enclave poético y concede a los elementos que en él incluye cualidades estéticas.
} 
bien podría signarse como un precepto de la alegría para el ciudadano del siglo XXI, igual que ya hicieran Epicuro, Séneca o Marcial en la época clásica:

\author{
El bien que está en tu mano, \\ que está en la mía y en la de cualquiera \\ y que tan solo necesita y busca \\ que haya en el corazón consentimiento \\ para llegar hasta la luz del día, \\ sabe cerrar heridas, cura daños \\ no ya a quien con asombro lo recibe \\ sino a la propia carne lacerada \\ y al retraído espíritu \\ (que ahora por fin se expande) \\ del que con decisión quiere que sea.
}

Abre entonces alguna
ventana de tu casa y, desde allí,
con ojo limpio mira
la tierra sueca de tu pobre huerto.
y podrás ver acaso
que, al abrigo del viento -en un rincón
en el que el sol se ha echado a descansar,
ovillado en el suelo como dócil
e inofensivo can de tu cercado-,
exultante se alza
una insólita flor de color púrpura,
flor de inocencia, flor inmarcesible
que de aquel bien se nutre y que celebra
tu pacto luminoso con la vida.

Relacionado con este poema cabe recordar, también, el perteneciente a La certeza (2005): «Luz que nunca se extingue», en el que el continuo del día se ve iluminado por una luz que, aunque aparentemente onírica, conecta con la realidad más cercana. En la poesía de Sánchez Rosillo, entonces, «lo real no es un ámbito conflictivo sino un mapa relacional en el que se gesta un modo de ser, sentir y actuar» (Sánchez Rosillo, 2014). La luz, es sinónimo de vida y de felicidad, pero también lo son las vivencias y objetos del paisaje cotidiano que le envuelve. La lenta y serena observación del entorno, en el caso del poeta murciano, es una honda característica que aparece presente en todos sus versos. De hecho, afirma en una entrevista: «el que mira con los ojos abiertos y sueña e imagina tiene ante sí toda la realidad, aunque él no esté en todas partes» (Azancot, 2015). El acto de la observación, por tanto, resulta una experiencia no solo estética, sino casi caleidoscópica e inmoviliza el tiempo en aras de acentuar el momento presente (Maffesoli, 2007: 89).

De entre esos espacios de la cotidianidad representados en sus obras, hay uno al que Sánchez Rosillo alude, implícitamente, de manera constante. Se trata, tal y como nos advierte José Luis Morante en una antología del poeta, de un caserón familiar en Campo de Montiel, herencia materna y en el que la familia disfrutaba durante los veranos, hasta que desgraciadamente fue vendido cuando el poeta contaba con dieciocho años de edad (Morante, 2014) ${ }^{11}$. En la notable importancia de este espacio en

\footnotetext{
${ }^{11}$ Así lo expone también Sánchez Rosillo, quien afirma: «Tan incomparable maravilla la perdí cuando mi madre, a la altura de mis dieciocho años, tuvo que vender la finca. Era yo por entonces un poeta en ciernes, y con la conciencia de la pérdida
} 


\section{Tropelías. Revista de Teoría de la Literatura y Literatura Comparada, 30 (2018) \\ Un pacto con la felicidad: resistencias íntimas en la última poesía de Eloy Sánchez Rosillo}

la poesía de Sánchez Rosillo ha insistido también Rubio Sánchez, quien afirma incluso que «es algo que aparece diseminado en toda su obra poética» (2011). Parece, entonces, que la felicidad que le otorga el recuerdo de dicho espacio de su infancia es lo que vincula el escritor a ese acto sinestésico que implica oír la luz (2008: 87):

Debo decir que cuando yo era niño
y en el campo veía la densa muchedumbre
de estrellas en los cielos del verano,
además de mirar tanto fulgor,
podía oír la luz: se escuchaba allí arriba
como un rumor de enjambre laborioso.

Este enclave es descrito por Morante como «[...] lleno de quietud. A la luz del verano, permitía a sus moradores un contacto directo con la naturaleza y el disfrute diario de la vida silvestre» (2014), lo que sin duda ya ofrece una clave importante acerca de la serenidad y felicidad que le concedía. En uno de sus poemas, declama: «[...] de nuevo retorno/ a aquella casa blanca cuyos muros se alzaban/ en medio de los campos,/ en el centro del mundo y del verano». Este retiro manchego, pues, resulta ser uno de los territorios poéticos por excelencia en la obra de Sánchez Rosillo, y conectado a él, los elementos que componían aquel espacio arcádico que, perteneciente a su infancia, recuerda en su etapa de adulto con ese tono de melancolía feliz y sosegada habitual ya en su obra. Así se puede observar en el texto «Allí y aquí», donde conecta el que parece ser aquel espacio y lo rescata en su recuerdo para mantenerlo vivo: «Los grillos de la infancia no cantan allí solo;/ también cantan ahora, y al oírlos escucho/ la música piadosa y dulce de la vida» (2013: 91).

Estos últimos versos nos trasladan inmediatamente al verano, no solo por saber que en aquel cobijo infantil pasara gran parte de la época estival, sino por la figura del grillo, que conecta con el canto pausado entre el silencio campestre. Pero, además, el verano es el momento de mayor luz, elemento que como ya se ha visto es neurálgico en la poesía de Sánchez Rosillo y que supone, asimismo, la epifanía del presente. Al respecto, destaca la siguiente declaración del autor en una reciente entrevista (Pelluz, 2017):

E.P.: En sus libros aparece mucho el verano y ha comentado que, en su juventud, pasaba el día leyendo al sol. ¿Por qué es tan importante para usted esta estación?

E.S.R.: El verano simboliza en mi poesía el momento en el que todo está más vivo y más pleno. Por eso me encanta porque, a parte, también se junta en nuestra tradición que es cuando menos trabajo tiene uno, cuando más disponible está para mirar el mundo, para escribir, para ver a la gente que pasa, las muchachas en la playa; entonces, claro, es una estación hermosa, aunque luego el calor de Murcia no sea cualquier cosa (risas).

El verano, por tanto, es el momento de mayor revelación e inspiración para el poeta, así como el alba, que de nuevo conecta con los recuerdos infantiles de Sánchez Rosillo, en cuyo poema «Aquellos años» puede leerse: «lo único que olía siempre a nuevo/ era la luz del sol cada mañana» (2015: 55). En sincronía con esta época y el caserón familiar, aparecerá también la figura del pájaro de forma

del paraíso empezó a fraguarme en el alma y en los poemas que escribía el mito del jilguero. El paso del tiempo me ha ido haciendo ver la importancia capital en mi vida de aquella criatura prodigiosa» (2012: 86). 
constante; en concreto, el jilguero o el mirlo serán los más habituales, si bien hay en los versos de Sánchez Rosillo toda una pajarería que merece ser atendida. Así lo considera Juan Marqués, quien en 2012 publicó En el árbol del tiempo, una pequeña selección de algunos de los textos del poeta murciano en los que vuelan y anidan todo tipo de aves, a través de cuyas imágenes el autor «ejercita la sorpresa sencilla y cotidiana en sus múltiples espejos de picos y vuelos por medio del verbo ágil y adjetivo exacto» (Galán, 2014: 102). Es el propio poeta quien, a modo de epílogo, redactó la «Nota sobre el jilguero» en la antología de Juan Marqués y en cuyas líneas expone (2012: 83:

Se preguntará el lector de este libro, o incluso quien apenas lo haya hojeado un poco, el porqué del muy notable predominio del jilguero entre los pájaros de mi poesía. Su hegemónica presencia se debe a que él fue sin duda, de todos sus congéneres, el que más de cerca y más intensamente viví en mi infancia y mi adolescencia. Nunca me canso de pensar en tan menudo y mágico ser y lo tengo en el corazón como pájaro tutelar.

Tanto el ruiseñor como el jilguero, igualmente, conectan a Sánchez Rosillo con una gran estirpe literaria que se remonta a la Antigüedad clásica y las Geórgicas de Virgilio, por ejemplo, y que tras pasar por Petrarca llega también hasta algunos de los poetas de la Generación del $27^{12}$, por citar tan solo los nombres más destacados ${ }^{13}$. Es notorio el caso del jilguero, que el mismo poeta afirma que era, después del gorrión, el pájaro más abundante en aquellas tierras manchegas de sus veranos (2012: 84) y que, junto a la luz del verano, constituyen los dos elementos de mayor confidencia y resistencia íntima en Eloy Sánchez Rosillo. Su poema «En mi nombre» es sumamente revelador al respecto, pues son ambos los acompañantes y cómplices del poeta a quienes confía, casi como de su propio testamento se tratase, la verdad de su vida (2012: 52):

\author{
Que la luz del verano y el jilguero \\ me defiendan a dúo \\ si levantan infundios sobre mí. \\ Me conocen de siempre \\ y saben la verdad sobre mi vida \\ mejor que nadie. Estoy casi seguro \\ de que no han de negarse \\ a abogar por mi causa. \\ También en mis poemas muchas veces \\ hablé de ambos lo mejor que supe. \\ Lo que ellos digan, vale. \\ Lo aceptaré sin más y por completo. \\ No añadiré palabra \\ ni moveré una coma.
}

El canto del jilguero, entonces, no solo es para él la verdad de su vida, sino también constituye el bien del mundo: «¿Cómo es posible que algo como eso, / tan frágil y tan puro, tan propio y tan de nadie, /pueda estar en la vida, ser la vida,/ que exista un bien tan grande y para siempre?» (2012: 79),

\footnotetext{
12 Este hecho es especialmente notorio con el caso de Luis Cernuda, a cuya obra dedicó Eloy Sánchez Rosillo su tesis doctoral en la Universidad de Murcia y que cristalizó publicada en el ensayo La fuerza del destino (2012).

${ }^{13}$ Resulta imprescindible recordar un libro de Salvador Novo como es Las aves en la poesía castellana (1953) que, a pesar de su longevidad, continúa siendo un texto de referencia y, sobre todo, una sobresaliente recopilación de esta tradición ornitológica vinculada a la literatura y que en el caso español ya aparece presente en el mismo Cantar del Mío Cid.
} 


\section{Tropelías. Revista de Teoría de la Literatura y Literatura Comparada, 30 (2018) \\ Un pacto con la felicidad: resistencias íntimas en la última poesía de Eloy Sánchez Rosillo} 149

hasta el punto de que, en el mismo poema, «En el árbol del tiempo», Sánchez Rosillo declama: «Para escuchar el canto del jilguero/ vine yo al mundo» (2012: 79). El mirlo, por otro lado, también constituye un canto alegre, pero asociado a la declinación del verano y de la luz del día, que para el poeta constituye un acto casi elegíaco o melancólico (2015: 63):

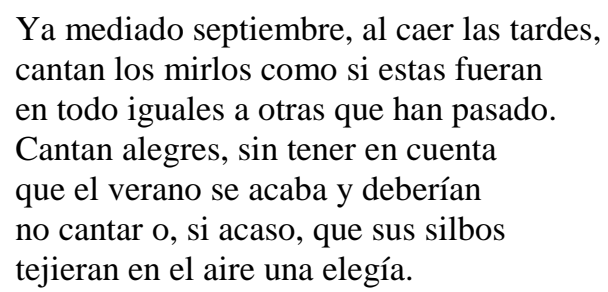

De cualquier manera, es evidente la notoriedad que presenta y que merece resaltarse tanto la figura del pájaro, en general, como del jilguero en particular; vinculado, eso sí, a la luminosidad del día y de la época estival. Al mismo tiempo, la infancia y adolescencia del autor están siempre presentes, pero no solo por ser la época en la que Sánchez Rosillo disfrutaba de aquel beatus ille que supuso para él la casa de campo familiar en La Mancha, sino también por constituir, en tanto que recuerdos, la certeza de que la melancolía y el dolor que por entonces sintiera no eran más que la negación de la luz y la alegría de todo cuanto le rodeaba, de lo meramente cotidiano y sencillo. Él mismo confirma este hecho en su particular «Oda a la alegría»: «La juventud ofusca y con frecuencia mueve/ de incomprensible modo a quien la ostenta/ hacia el dolor y le melancolía» pero ahora, en su etapa madura, enuncia después: «Pero ya no me engaño y te discierno/ suave o vibrante, arrebatada o dulce,/ irresistible y mágica alegría» (2015: 141-142).

\section{Conclusiones}

En su famosa «Carta sobre el humanismo», Martin Heidegger nos acerca a una anécdota transmitida a través de un texto de Aristóteles y en la que se refiriera a Heráclito, según la cual un grupo de forasteros fueron a visitar a este último a su casa, en la que encontraron al filósofo calentándose junto a un horno. La escena provocó el estupor y la sorpresa en aquellos que esperaban encontrar a Héraclito en una concepción que aún hoy en día reside en el mundo cultural e intelectual: el del sabio como un personaje exótico y casi mesiánico, superior a los mortales que ellos consideraron ser. Sin embargo, fue la proximidad de lo cotidiano lo que encontraron, a cuya llegada el filósofo los invitó a entrar diciéndoles: «También aquí están presentes los dioses» (Heidegger, 2007: 290). El elemento de lo cotidiano, por tanto, también emerge en el plano cultural y, en el caso concreto que aquí ocupa, el poético. Así ocurre con Eloy Sánchez Rosillo, por cuyos versos transcurre el devenir diario, algo especialmente notorio en su producción de los últimos años. Esta, como ya se ha expuesto, ha experimentado un giro acorde con su concepción del tiempo, tanto poético como vital. En tan solo unas líneas, Prieto de Paula resume de forma sobresaliente este recorrido del autor murciano (2007: 112): 
Un libro tras otro se ha ido aclarando el sentido de su evolución: tras los dos primeros títulos (Maneras de estar solo y Páginas de un diario), el poeta alcanza a divisar un primer desmonte de derrumbes en Elegías, se adentra en los aconteceres de la cima existencial en Autorretratos, condensa la experiencia trágica del desmoronamiento en La vida y, en La certeza, atraviesa los trampantojos de la apariencia hasta alcanzar una iluminación contemplativa.

De cualquier forma, es evidente que a partir del año 2005 y con la publicación de La certeza, el tono elegíaco declina a favor del canto hímnico y celebratorio, quizás, precisamente, porque la juventud es mucho más melancólica en un sentido ontológico y de ello es plenamente consciente Sánchez Rosillo. Asimismo, la «estética de la claridad» (Pozuelo Yvancos, 2007) que caracteriza su última poesía y que lo aleja de ciertas tendencias más cercanas al culturalismo conecta con una estética que cada vez presenta más adeptos en la poesía española contemporánea, donde una poética del bien, de la alegría y de la serenidad muestra su deseo de superar ciertos discursos más cercanos al mal o al pesimismo procedentes del siglo pasado.

Así pues, Eloy Sánchez Rosillo «transmite un gozo sereno, mesurado, que tiene la misión de impregnar todo lo que vive, con la intensidad de la fina lluvia que es capaz de refrescar los recuerdos» (Lanseros Sánchez, 2017), y ello lo hace a través de dos cuestiones, principalmente: los recuerdos de la infancia y el símbolo de los pájaros, entre los que destaca el jilguero. La presencia de ambos elementos conecta en un espacio de la niñez y adolescencia del poeta en el que pasaba los veranos junto a su familia y que posee una omnipresencia en toda su obra poética que siempre vincula a un enclave de felicidad y serenidad, donde la luz del día signa toda esa alegría como vehículo y como enlace entre todos sus libros. Estos elementos, además, se erigen en términos de «resistencia íntima» —aludiendo de nuevo al concepto planteado por el profesor Josep Maria Esquirol—y ayudan al poeta a vislumbrar un panorama más amable y más humano ante la cultural del malestar preponderante del siglo XXI.

\section{Bibliografía}

BACHELARD, Gaston (1979), L'intuition de l'instant. Gonthier, Méditations.

BAGUÉ QUíLEZ, Luis (2003): «La recuperación del sentido clásico en la última poesía española», Hesperia. Anuario de Filología Hispánica, 6, pp. 27-41.

(2008): «La poesía después de la poesía. Cartografías estéticas para el tercer milenio», Monteagudo, 13, pp. 49-72.

CAMBronero Armero, Verónica (2012): «Algunas pinceladas sobre Sueño del origen de Eloy Sánchez Rosillo», Tonos. Revista Electrónica de Estudios Filológicos, 22; en https://www.um.es/ tonosdigital/znum22/secciones/resenas-1-cambronero_eloysrosillo.htm (última consulta, 03-092017).

ESQUIROL, Josep Maria (2015): La resistencia íntima. Ensayo de una filosofía de la proximidad. Barcelona, Acantilado. 
FAJARDO, Roberto (2007): «Arte, utopía y el espacio intermediario: el espacio de las formas simbólicas», Fedro. Revista de Estética y Teoría de las Artes, 5; en https://institucional.us.es/ fedro/uploads/pdf/n5/fajardo.pdf (última consulta, 03-09-2017).

FANJUL, Cristina (2013): «La poesía es un territorio que salva de la intemperie», Entrevista a José Luis Puerto, Diario de León; en http://www.diariodeleon.es/noticias/cultura/la-poesia-es-territoriosalva-intemperie 760959.html (última consulta, 03-09-2017).

FONTANA, Antonio (2013): «¿No tiene usted preguntas menos enrevesadas?», Entrevista a Eloy Sánchez Rosillo, ABC Cultural; en http://www.abc.es/cultura/cultural/20130624/abci-eloysanchez-rosillo-tiene-201306241412.html (última consulta, 03-09-2017).

GALÁN, Julio César (20149: «La pajarería de Eloy Sánchez Rosillo», Cuadernos Hispanoamericanos, 764, pp. 101-105.

GARCÍA-BARÓ, Miguel (2012): Sentir y pensar la vida. Ensayos de fenomenología española. Madrid, Trotta.

GARCÍA Montero, Luis (1996): Aguas territoriales. Valencia, Pre-Textos.

LANSEROS SÁNCHEZ, Raquel (2017): «La luz de un poeta inclasificable: evolución de la poesía de Eloy Sánchez Rosillo a través de su propia concepción del tiempo», Tonos digital, 32; en http://www.tonosdigital.com/ojs/index.php/tonos/article/view/1619 (última consulta, 03-092017).

MAFFESOLI, Michel (1996): De la orgía: una aproximación sociológica. Trad. Manuel Mandianes. Barcelona, Ariel.

- (1993): La contemplation du monde. Figures du style communautaire. Paris, Grasset.

MAGRIS, Claudio (2001): Utopía y desencanto: historias, esperanzas e ilusiones de la modernidad. Trad. J. A. González Sainz. Barcelona, Anagrama.

Mora FANDOS, José Manuel (2017): «Cada poema escrito es solo una cristalización de la poesía que existe en el mundo», Entrevista a Eloy Sánchez Rosillo, Nueva Revista de Política, Cultura y Arte; en http://www.nuevarevista.net/articulos/sanchez-rosillo-cada-poema-escrito-es-solo-unacristalizacion-de-la-poesia-que-existe-en-e (última consulta, 3-09-2017).

MuÑOZ, Jacobo (2002): Figuras del desasosiego moderno: encrucijadas filosóficas de nuestro tiempo, Boadilla del Monte, Antonio Machado Libros.

Novo, Salvador (1953): Las aves en la poesía castellana. México, Fondo de Cultura Económica.

PELLUZ, Mónica (2017): «Tengo que dar hasta la última gota de mi sangre en el cumplimiento de esta vocación», El Periodicum; en http://www.elperiodicum.es/cultura/eloy-sanchez-rosillo-tengoque-dar-hasta-la-ultima-gota-de-mi-sangre-en-el-cumplimiento-de-esta-vocacion/ (última consulta, 3-09-2017).

Pozuelo Yvancos, José María (2007): «Figuraciones del yo en la poesía de Eloy Sánchez Rosillo», en Ricardo EscaVy ZAMORA, ed., La poesía de Eloy Sánchez Rosillo: el ruido del tiempo. Murcia, Universidad de Murcia, pp. 29-50. 
PRIETO DE PAUla, Ángel L. (2007): «La elegía y la construcción del presente en Eloy Sánchez Rosillo», en Ricardo EsCAVy ZAMORA, ed., La poesía de Eloy Sánchez Rosillo: el ruido del tiempo. Murcia, Universidad de Murcia, pp. 99-112.

RIECHMANN, Jorge (2013): El siglo de la gran prueba. Tequeste, Baile del Sol.

SÁnCHEZ Rosillo, Eloy (1992): La fuerza del destino. Vida y poesía de Luis Cernuda. Murcia, Secretariado de Publicaciones e Intercambio Científico - Universidad de Murcia.

- (2005a): Poética y poesía. Madrid, Fundación Juan March.

- (2005b): La certeza. Barcelona, Tusquets.

- (2011): Antes del nombre. Barcelona, Tusquets Editores.

- (2012): En el árbol del tiempo. Valencia, Pre-Textos.

- (2013): Sueño del origen. Barcelona, Tusquets.

- (2014): Hilo de oro: antología poética (1974-2011). Madrid, Cátedra.

- (2015): Quién lo diría. Barcelona, Tusquets.

VV. AA. (2011): Poesía ante la incertidumbre. Antología (Nuevos poetas en español). Madrid, Visor. 